\title{
Beyond CME: Diabetes Education Field-Interactive Strategies from Sweden
}

\author{
MARILYNN M. ROSENTHAL, PhD \\ Program in Health and Society \\ University of Michigan at Dearborn \\ Dearborn, Michigan \\ ANITA CARLSON, BA \\ URBAN ROSENQVIST, $M D, P h D$ \\ Diabetes Educational and Training Unit \\ Karolinska Hospital \\ Stockholm, Sweden
}

The Diabetes Educational and

Training Unit (DETU) at

Karolinska Hospital is a

permanent, continuing medical

education unit working with

general practitioners and nurse

teams from Stockholm's neigh-

borhood health centers. It offers a

two-week educational program

four times a year, teaching a

comprehensive approach to

diabetes care. Evaluation

research found that centers that

had implemented the approach taught at the CME course had excellent staff rapport and produced patients who were more knowledgeable about their disease and better able to engage in self-care. As a result of this research, the Stockholm DETU has added innovative fieldinteractive strategies to stimulate centers that have not implemented the program. These strategies include techniques to enhance staff rapport, increase knowledge and interest in care for people with diabetes, and arrive at staffdetermined approaches for organizing diabetes care. Initial evaluation of these strategies indicate encouraging results.
In 1980, the Stockholm County Diabetes Education and Training Unit (DETU), a permanent diabetes continuing medical education (CME) unit, was established in the Endocrinology Department at Karolinska Hospital in Stockholm, Sweden. Its goal is to promote comprehensive community care for people with noninsulin-dependent diabetes mellitus (NIDDM).

Until recently, the Swedish health care system was hospital, specialist, and high technology oriented, much like its counterpart in the USA. There are several major differences, however: the Swedish system is public, physicians are on salary, and access to care is a right of citizenship. Since the late 1970 s, a concerted effort has been made to build the primary care sector and move as much care as possible out of the hospitals. So, for example, neighborhood health centers have expanded rapidly in Stockholm County, from 46 in 1978 to 110 by 1985 . These centers stress care given by health teams that include general practitioners (GPs), nurses, and other appropriate staff. It is the task of DETU to support and improve the work of the teams in the care of their diabetic patients.

A new diabetes education program written in 1977 by Sweden's leading diabetologist ${ }^{\prime}$ (and revised periodically) is taught at the DETU in four annual two-week sessions. The program combines current biomedical information about diabetes, details of diet and foot care, techniques for patient education, role responsibilities among members of the health team, and support routines for organizing care at the centers (Table 1). One week of each session is spent on classroom work that combines lectures, case studies, and problem solving. There is particular emphasis on a set of organizational

Dr Rosenthal is director of the Program in Health and Society at the University of Michigan at Dearborn. Ms Carlson is a staff psychologist and Dr Rosenquist is director of the Diabetes Educational and Training Unit at Karolinska Hospital.

This research is supported by grants from the Wenner Gren Foundation; Swedish Medical Research Council grants 7542 and 06615; the Karolinska Institute; King Gustaf V and Queen Victoria's Fund; The Swedish Diabetes Federation; and the Nordic Insulin Fund.

Reprint requests to Marilynn M. Rosenthal, $\mathrm{PhD}$, Director, Program in Health and Society, University of Michigan at Dearborn, 4901 Evergreen Road, Dearborn, MI 48128. 
Table 1. Schedule for the Two-Week Teaching Program

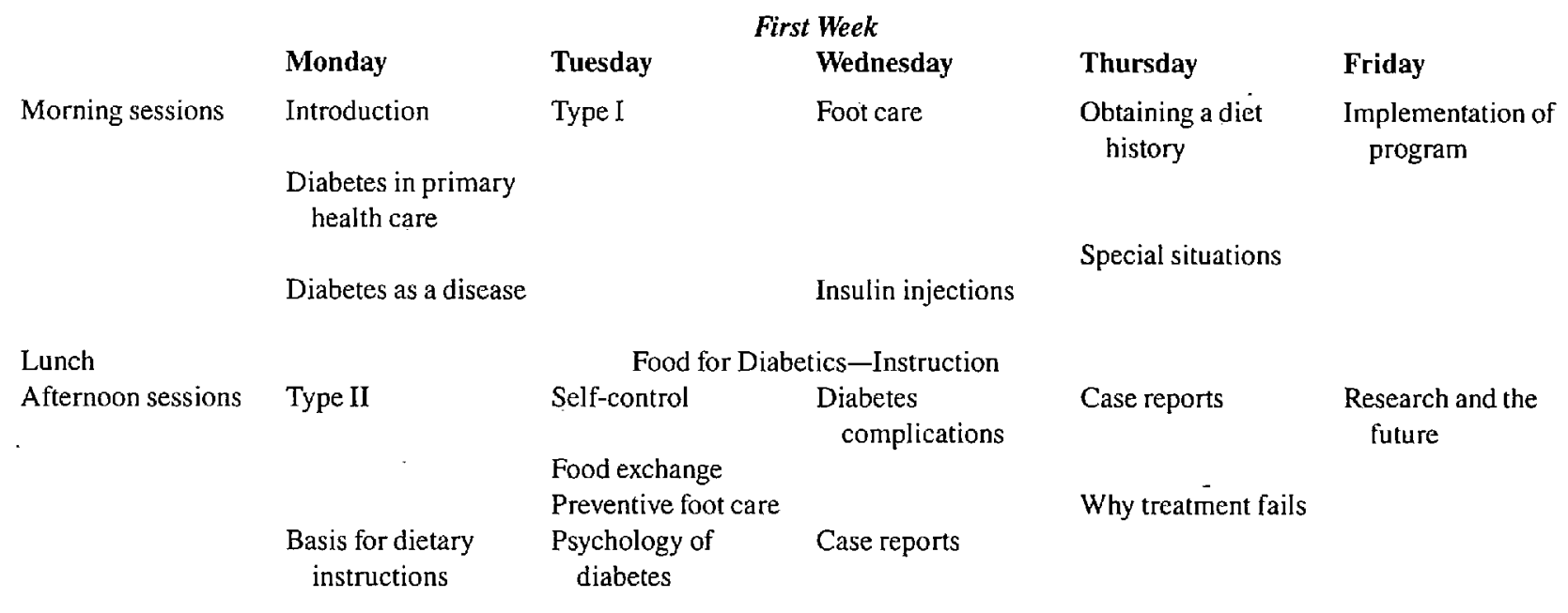

\section{Second Week}

Participants are assigned to specialists in the diabetes units of their referral hospitals where they assist in the care of in-patients and take part in hospital educational programs. This deepens their knowledge of the disease and helps establish a link with physicians to whom they will be making referrals.

Table 2. Health Care Center Acceptance of Support Routines 1983-85

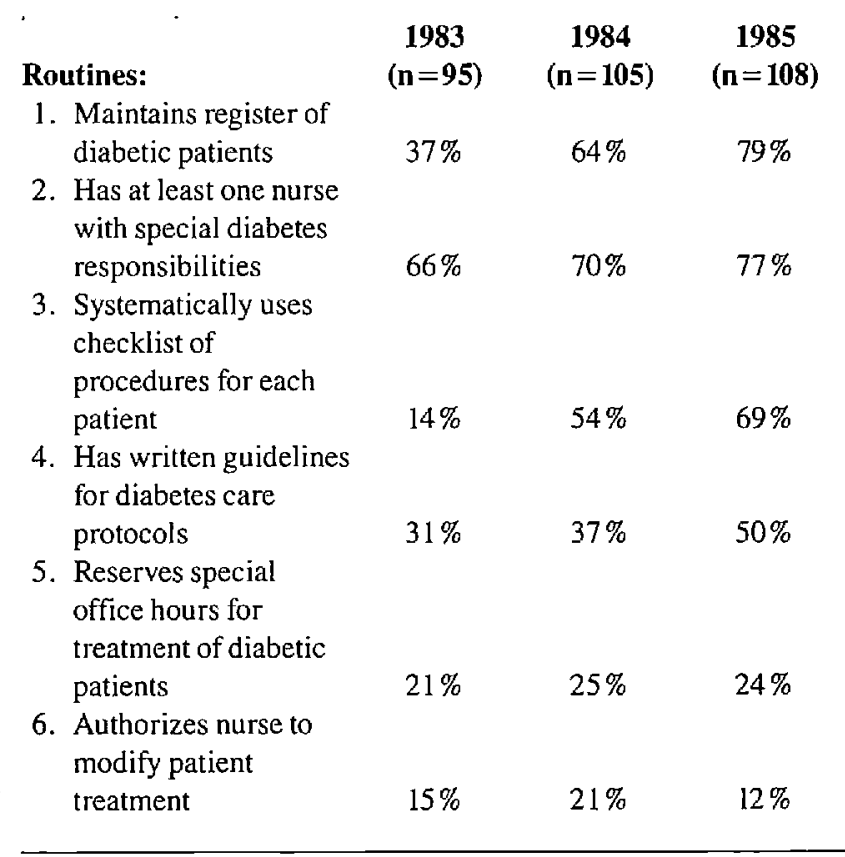

support routines established in the original teaching program and considered essential to guarantee good care (see Table 2 for list of support routines). A second week is spent in a hospital diabetology department learning more about the medical aspects of the disease.

Since DETU's inception, GP and nurse teans from $86 \%$ of the centers have attended the two-week educational course. All center staff (ranging from two to seven teams) are salaried employees of the county, which has the major administrative and financial responsibility for the entire health care system. Staff members have fully paid CME leaves to attend such courses and, because of this, there is considerably better CME involvement than reported in other countries.' This also means there is more time to participate in CME experiments. Therefore, the Swedish system provides a unique opportunity to study the impact of innovative approaches that would be difficult to institute in the United States.

Cognizant of the problems in conducting effective CME courses, ${ }^{3-5}$ the developers of DETU's education course chose to emphasize case presentations and problem-solving techniques. In addition, the center remains in touch with attendees through telephone availability, visits to the health centers, and a six-month follow-up visit to each team that has attended a course. These three techniques for getting feedback from the field are used to evaluate the impact of the educational course and modify it to meet needs noted from conversations and observations at the health centers. DETU thus attempts to evaluate its work by observing actual practice rather than evaluating knowledge retention after the course.

DETU has also conducted several waves of extensive, systematic research to establish the extent to which the routines it recommends have been implemented and how patient outcomes are affected.

\section{Research Efforts}

First Phase: Methodologies In 1983, 1984, and 1985 , DETU surveyed directors of all Stockholm primary health care centers that had been established for at least one year. It was felt that a survey of directors would help direct attention to diabetes care in their own center. The questionnaire determined how many GP-nurse teams had attended the course and how many of the six routines taught in the course were being used in conjunction with care for persons with diabetes. By using telephone reminders. DETU achieved a 
Table 3. Characteristics of the Two Groups of Primary Health Care Centers (PHCC)

\begin{tabular}{lcc} 
& $\begin{array}{c}\text { Centers With } \\
\text { Program } \\
(\mathbf{n}=10)\end{array}$ & $\begin{array}{c}\text { Centers } \\
\text { Without } \\
\text { Program } \\
(\mathbf{n}=10)\end{array}$ \\
Staff employed $\geq 6$ months & 3.0 & 3.2 \\
$\quad$ Physicians (No./PHCC) & 3.7 & 3.7 \\
Office nurses (No./PHCC) & 4.4 & 5.6 \\
$\quad \begin{array}{c}\text { District nurses (No./PHCC) } \\
\text { No. diabetic patients/PHCC }\end{array}$ & 100.6 & 145.7 \\
No. support routines & & \\
(mean \pm SEM) & $5.0 \pm 0.3$ & $1.6 \pm 0.4 *$ \\
& & \\
${ }^{*} P<.001$ & & \\
\hline
\end{tabular}

response rate of $100 \%$. Each center had at least one GP and one nurse who had attended the course. By 1985 , at least $50 \%$ of the centers had four or more of the routines in place (Table 2). The routines with the least acceptance are those involving special hours for persons with diabetes and nurse modification of patient treatment.

Based on the survey results in 1983, DETU identified ten centers with diabetes programs almost fully in place. "Fully in place" was defined as utilizing at least four or more of the routines. These centers were compared with ten others drawn from a random sample of all the remaining centers. The latter were designated centers "without the program" in place. The 20 centers were studied with reference to organizational, staff, and patient factors. Basic characteristics of the two groups of centers are shown in Table 3.

Questionnaires were sent to the GPs and nurses; response rate was $87 \%$. These questionnaires explored staff relations, staff communications, general working atmosphere, time spent in staff meetings, and time devoted to CME.

A $10 \%$ random sample comprising 196 patients was selected from the entire diabetic patient population of all 20 primary health care centers. These patients were given physical examinations and laboratory tests to determine glycosylated hemoglobin $\left(\mathrm{HbA}_{\mathrm{lc}}\right)$, serum creatinine, and urinary protein values. In addition, patients filled out questionnaires that established self-perception of illness, self-reported symptoms, extent of their diabetes education, their ability to identify unsuitable foods, and the degrees of self-care. The patient questionnaire had been pretested to strengthen the validity of the items. In addition, the questionnaires were discussed with the patients when they returned them to minimize any misunderstandings. We have no evidence that the two patient groups understood the questionnaire differently.

Overall, the research methodology permitted gathering data on organizational behavior at the health centers and on patients' outcomes.

First Phase Results of particular interest to DETU was the difference in organizational behavior between the ten centers that had the program in place and the ten centers without the full diabetes program in place. The ten centers without the program in place were found to have fewer staff meetings, less general continuing medical education, poor intrastaff communications, and less satisfaction with work in general. Although staff members had attended the diabetes course at DETU, these centers were more likely to identify a lack of knowledge about diabetes and a desire for more contact with diabetes specialists. (Note: $24 \%$ of staff members at centers without the program had attended the DETU course; the corresponding figure for the centers with the program was $36 \%$. $)^{3,4}$

The random sample of patients comprised 76 subjects from ten centers with the program and 120 from ten centers without the diabetes program. The two groups of patients were comparable with reference to sex and the following social indicators: education; income; degree of employment; housing; and whether or not they lived alone. The patient group from centers with the program were significantly younger than the other group $(64.0 \pm 0.4 v 67.5 \pm 0.3 ; P<.001$; mean \pm SEM). The mean age at onset of diabetes was 58 and 60 years, respectively. The percentage of insulin-dependent diabetes mellitus was $11 \%$ in centers with the program and $13 \%$ in the other group.

There were significant differences in patient outcomes. Patients from the centers with the program were more often instructed on a wider range of appropriate subjects. They were more knowledgeable about their disease; they were more skilled in their own care; they self-tested more often; and they were more confident that they could plan ahead effectively to forestall hyperglycemia. They also used the health team more effectively than did patients at the centers without the program. The patients at the centers with the program reported getting information as often from the nurse and dietitian as from the GPs. ${ }^{3,4}$ Tables 4-6 provide details of the comparison between centers with and without the program.

The patients at centers with the program also used less medication and were more likely to be treated with diet (Fig 1). ${ }^{3,4}$

The data on patients' physical condition showed no significant differences between the two groups of centers, however.

Table 4. Patient Education at Centers With and Without Program, 1983-84

$\begin{array}{cc}\text { With } & \text { Without } \\ \text { Program } & \text { Program } \\ (\mathbf{n}=76) & (\mathbf{n}=120)\end{array}$

Percent of patients reporting receiving instruction about

Diet

$79 \%$

Exercise

67

Alcohol abuse

61

Foot care

57

How to test for sugar

Medication (tablets)

Medication (insulin)

Injection methods

Late complications

Patients able to recognize unsuitable foods

54

51

14

9

6

$68 \%$

$58 \% *$

$44 * *$

45

$24 * * *$

$26 * * *$

39

10

$13 *$

3

$* P<.05 \quad * * P<.01 \quad * * * P<.001$ by $X^{2}$ analysis. 
Table 5. Patient Self-Care Behavior and Attitudes at Centers With and Without Program, 1983-84

Self-testing behavior
$\begin{aligned} & \text { Percentage of patients that } \\ & \text { reported testing more than } \\ & \text { twice a month }\end{aligned}$

Table 6. Patient Sources of Information at Centers With and Without Program, 1983-84

$\begin{array}{lcc} & \begin{array}{c}\text { With } \\ \text { Program } \\ (\mathbf{n = 7 6 )}\end{array} & \begin{array}{c}\text { Without } \\ \text { Program } \\ (\mathbf{n = 1 2 0})\end{array} \\ \text { Nurse } & 22 \% & 7 \% \\ \text { Physician } & 21 & 51 \\ \text { Dietitian and physician } & 15 & 18 \\ \text { Nurse and physician } & 15 & 4 \\ \text { Dietitian } & 13 & 11 \\ \text { Nurse and dietitian } & 6 & 2\end{array}$

The laboratory results were comparable except for the creatinine test where "without-program" patients had slightly higher values. ${ }^{3,4}$ Table 7 reflects the similarities in physiological measures. A number of unknown factors appear to be acting as intervening variables.

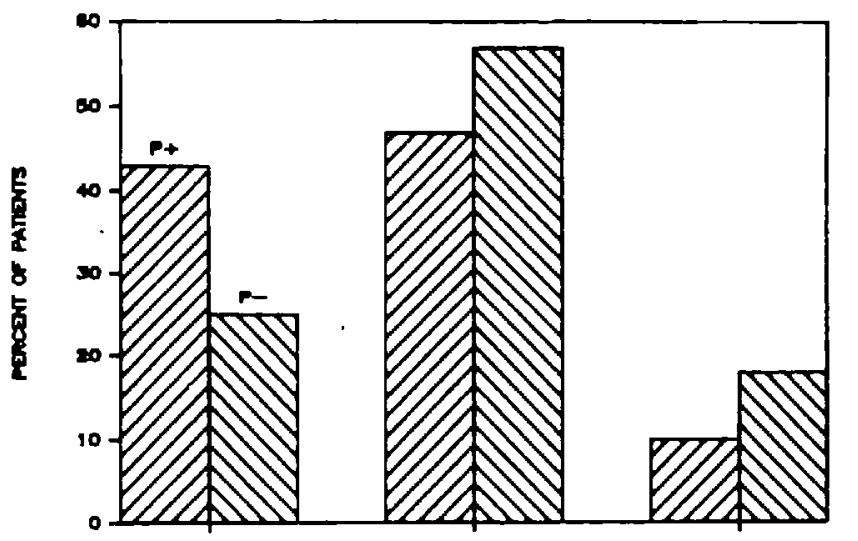

\section{Diet Tablets Insulin}

Fig 1. Relative use of diet, tablets, and insulin at centers with the program $(P+)$ and centers without the program $(P-)$. Results are based on a $10 \%$ sample of parients in each category of health care center.
Table 7. Patient Outcomes: Physical Condition and SelfReported Symptoms of Patients ät Centers With and Without Program, 1983-84
Self-reported symptoms

Angina pectoris

Have had myocardial infarction

Had proteinuria

Claudicatio

Reduced perception of touchfeet

Reduced vision because of diabetes

Physical examination results

Height-length index

Blood pressure systolic $(\mathrm{mm} \mathrm{Hg})$ diastolic ( $\mathrm{mm} \mathrm{Hg}$ )

Reduced perception of vibration-toe

Reduced perception of touchfoot

Loss of Achilles heel reflex

Feet

Loss of hair
Signs of pressure
Ulcers
Gangrene

Laboratory results

$\mathrm{HbA}_{\mathrm{Ic}}$ (\%)

Creatinine (S) $(\mu \mathrm{mol} / \mathrm{L})$

Albumin (U) (g/L)
With

Program

$(n=74)$

$16.4 \%$

9.6

9.5

8.3

Without Program $(n=119)$

7.0

$33.3 \%$

12.7

15.4

11.9

18.0

13.0

27.0

$1.16 \pm 0.03$

1. $12 \pm 0.02$

$159 \pm 2$

$165 \pm 2$

$87 \pm 1$

$91 \pm 5$

$15.1 \%$

$30.8 \%$

\section{4. $1 \%$}

$10.3 \%$

$8.2 \%$

$9.3 \%$

$39.2 \%$
44.6

$60.5 \%$

5.4

0

(3.5

3.4

1.7
$9.7 \% \pm 0.2 \%$

$94.7 \pm 2.5^{*}$

$87.1 \pm 2.1$

$0.01 \pm 0.02$
$* P<.05$ by $t$-test.

Discussion The Stockholm DETU has already incorporated some of the significant research findings on CME in the USA and other countries. It utilizes state-of-the-art educational techniques, and it has tried to monitor changes in medical practice in the field. It has been able to demonstrate progress in the implementation of the support routines it suggests for the organization of diabetes care at the county health centers. In a five-year period of time, since the first DETU course was taught in $1980,50 \%$ of the now 108 centers have at least four of the support routines in place. These are encouraging results. The two remaining support routines may be difficult to implement because they run counter to policy directives about primary health care center organization that have come down from the county central administration.

However, while progress is demonstrated in implementation of the support routines for diabetes care that DETU recommends, there are deterrents lodged in the organizational features of the centers with the lowest implementation of the routines. Staff questionnaire responses indicated that these deterrents included poor communications among staff, few staff meetings, little staff in-service training, and general dissatisfaction with the level of staff teamwork. 
The impact on patient outcomes is mixed. While the centers with the program are also the centers with more knowledgeable and motivated patients, physical outcomes are not significantly different from those at centers without the program. The Swedish CME effort is able to demonstrate some improvement in patient outcomes, but these findings represent limited improvements.

The ambiguities about correlations between CME, improved practitioner practices, and better patient outcomes are the same in Sweden as in the USA. ${ }^{5,6}$ These Swedish findings are of interest from an American point of view because the DETU has a permanent educational relationship with a defined population of medical practitioners. This is not generally true in the USA, except for Veterans Administration physicians and the Indian Health Service.

The Swedish findings suggest that some of the stumbling blocks to improving care and patient outcomes lie in the nature of the clinical environment as much as in the nature of the CME program. This research suggests that the clinical setting demands not only close scrutiny but specific efforts for change. This finding is more powerful in the Swedish setting because of the continuity of the CME unit. It also suggests the complexity of the large processes involved and a differential interaction of multiple factors that include the CME program, the process of knowledge transfer, organizational characteristics, and patient behavior.

Second Phase: Methodologies As a result of these findings, DETU has initiated a highly intensive field strategy designed to reduce the deterrents to quality diabetes care among health center staff.' The field strategy encompasses a multi-step series of meetings, innovative discussion techniques, and interviews on site in the centers, designed to stimulate more concrete analysis of how diabetes care is currently carried out and how it could be improved. The strategy involves five steps carried out before staff attend the course.

Step One An information meeting is held with the entire primary health center staff to explain the whole program leading to attendance at the two-week course.

Step Two Interviews (one hour in length) are carried out with all the GPs, selected nurses, administrators, laboratory technicians, and patients. The purpose is to ascertain their views of current care for people with diabetes, and possible improvements.

Step Three The interviews are analyzed and summarized, emphasizing strengths, weaknesses, and ideas for improvement of current diabetes approaches.

Step Four The summaries are sent back to each person interviewed.

Step Five All those interviewed attend a second meeting, held at their own center, during which they participate in a "conceptual modeling" session led by a DETU staff member. This is a dynamic discussion technique that encourages the uninhibited expression of each person's perception of how diabetes care is carried out. What inevitably emerges are the differences in perception between staff members and a growing awareness of gaps and inconsistencies in care. A unique feature of this intense discussion technique is the inclusion of patient representatives.

The participants are asked to formulate an individualized plan for their center. They bring this plan to the two-week
CME course for further refinement. A detailed analysis of interviews, conceptual modeling discussions, and follow-up questionnaires at the first six centers to go through the new field strategies and the course provides a preliminary assessment of its impact in increasing commitment to diabetes care. $^{7}$

Second Phase Results Findings indicate that there is a small increase in the adoption of DETU support routines. However, of greater significance is implementation of individualized plans. These plans usually included many more than the six support routines recommended at the DETU course, but well within the parameters and goals of the DETU program. In the first six centers, $84 \%$ of the individualized plans were implemented after one year. Closer examination of the plans formulated by the primary health care centers showed that, to a great extent, these centers had addressed the same organizational issues as the external criteria. However, the plans were detailed and tailored for each center and integrated existing services. Furthermore, a third of the plans were aimed at refining existing routines. In fact, the local programs were more ambitious and richer in content than called for by the external criteria. Overall, the five-step field strategies was successful in stimulating further, more comprehensive development of diabetes care programs in the six centers but in varied forms, rather than strictly according to the model promoted by the DETU continuing medical education diabetes program.

\section{Discussion}

Because of the nature of the Swedish public health care system, it has been possible to establish a permanent diabetes care continuing medical education unit to teach a health team approach to general practitioners and nurses in the rapidly expanding primary health care centers in Stockholm, Sweden. The CME unit, in place since 1980 , has been able to evaluate its teaching efforts to ascertain the extent to which the program it teaches has been implemented.

The first phase of its evaluation ascertained that patients in the centers where the program has been implemented are more knowledgeable and engage in more self-reported selfcare than patients in centers without the program. There are, however, few differences in physical outcomes. Research also indicated that there were deterrents to implementation in the centers without the program fully in place: eg, poor intrastaff communication and dissatisfaction with opportunities for cooperation. ${ }^{8}$ To stimulate further implementation of the program, DETU developed a series of field-interactive strategies that emphasize intensive discussion and selfanalysis. A second phase of evaluation research documents an increase in program implementation, particularly where centers can innovate to meet their own situations and perceptions. This has led the DETU to modify its original CME approach.

An essential lesson should be noted: continuing medical education efforts alone are not sufficient to change physician practice and effect patient outcomes. Even pedagogical innovations in CME will not produce desired results unless they are linked to an understanding of the organizational structure of medical practice and efforts to modify that organizational structure. 
This finding is similar to those discussed in the article by Mazzuca in the 1986 Special Issue of The Diabetes Educator. ${ }^{9}$ Mazzuca stresses incentive and disincentive strategies in the clinical environment. The Swedish research concerns itself with organizational communication and work environment as experienced by staff. These are complementary and interrelated observations.

The Swedish experience and research suggest some specific recommendations for CME directors. These include:

1. Attention to the quality of the CME program, both substance and teaching style

2 . The need to innovate new teaching approaches, sometimes in the clinical setting

3. Attention to organizational barriers in the clinical environment

4. Strategies to change the clinical environment

5. Inclusion of the patient where possible in the entire process

6. The need to stimulate providers and patients to create their own innovations so that they "own" the change process itself

The Diabetes Education and Training Unit will continue to offer its two-week educational course, modifying the curriculum as its staff notes changing needs or deficiencies in how the health centers manage people with diabetes. DETU will continue its annual questionnaire survey of all the centers in the county to monitor the further implementation of its diabetes care routines. There will be special interest in watching the centers that have been exposed to "conceptual modeling," both in terms of how diabetes care is organized and the effect on patient outcomes.

The Stockholm DETU has reinterpreted its CME activities to reach into the field of medical practice in the primary health care centers. It is committed to expanding educational efforts with field-intensive strategies to improve care for diabetic patients. As such, it is a pioneering effort in continuing medical education by linking it to the organizational aspects of medical practice.

\section{References}

1. Luft R. Underlag till värdprogram för diabetes. Stockholm: Socialstyrelsen, Vardprogramnämnden, 1977. (Basis for medical care program for diabetes. Stockholm: National Board of Health and Welfare, Medical Care Program Working Group, 1977.)

2. Barham PM, Benseman J. Participation in continuing medical education of general practitioners in New Zealand. Med Educ 1984;60:649-54.

3. Rosenquist U, Carlson A. Organiserad Diabetesvärd ger Effekt. Rapport avseende utvärdering av Värdprogram fór Diabetes, 1984. Landstingets undervisningscentrum for diabetes, Karolinska sjukhuset. (Organized diabetes care medical program 1984. County Council Diabetes Education and Training Unit, Karolinska Hospital, Stockholm, Sweden.)

4. Rosenqvist U, Carlson A, Luft R. Concept, planning and implementation of diabetes health care in Sweden. Int Diabetes Fed Bull 1986;31:99-102.

5. Haynes RB, Davis DA, McKibbon AA, et al. Critical appraisal of the efficiency of continuing medical education. JAMA 1984;252:61-64.

6. Bashook PE. Future directions in continuing education. Diabetes Educ 1986; 12:215-18.

7. Carlson A, Rosenquist U. Conceptual modeling in the development of diabetes care in primary health care. LUCD Report No. 3. Stockholm: Karolinska sjukhuset, 1985.

8. Carlson A, Rosenqvist U. Diabetes control program implementation. On the importance of staff involvement. Scand J Primary Health Care (in press).

9. Mazzuca, SA. The role of the clinical environment in the translation of research into practice. Diabetes Educ 1986:12:219-24. 